Volume 14, Issue 1, pp.260-268, 2013

\title{
A LONGITUDINAL STUDY OF ENROLLMENT TRENDS AND GRADUATION GPAs FOR MEN AND WOMEN IN CIS PROGRAMS
}

\author{
Sushma Mishra, Robert Morris University, mishra@rmu.edu \\ Peter Draus, Robert Morris University,draus@rmu.edu \\ Donald Caputo, Robert Morris University, caputo@rmu.edu \\ Gregory Leone, Robert Morris University, leone@rmu.edu \\ Fred G. Kohun, Robert Morris University, Kohun@rmu.edu \\ DianaRepack, repack@comcast.ne
}

\begin{abstract}
Despite expanding opportunities, women are increasingly demonstrating a lack of interest in computer-related majors at the undergraduate level at virtually every American university. This research study focuses on enrollment characteristics of females entering computer studies (IT/IS) over a period of 12 years at a mid-sized university. The salient factors being tested by gender are the incoming SAT (Math, Verbal and Total) scores and the final outgoing GPA scores at the conclusion of the student academic experience. Thus aptitude is correlated with performance for a direct statistical comparison by gender. Pattern differences, also by gender, are examined at the enrollment stage. Additionally, salient factors such as demographic and professional characteristics, work-life balance, contextual influences, positive experiences, family and teacher influences, stereotypical connotations, prior usage, and negative life-style aspects are woven into the fabric of the research endeavor.
\end{abstract}

Keywords: Women in computing, ANOVA, GPA, SAT, academic preference, information technology

\section{INTRODUCTION}

Women earning computing degrees in universities throughout the nation, and subsequently entering the work force in computing related jobs in the United States are severely underrepresented. In 2003 and 2004 in the United States, male students who earned bachelor degrees in information sciences and computing outnumbered females by nearly 3 to 1 (U.S. Department of Education, 2005). Conversely, more women are completing their college education than men. In 2003 and 2004 more than 800,000 women received bachelor's degrees compared to less than 600,000 men receiving bachelor degrees (U.S. Department of Education, 2005). There is a need for increased numbers of women to be enrolled in undergraduate information systems or computing related programs. The population of women receiving undergraduate degrees has increased significantly when considering the entire decade from 2000 through 2010. It reached was an all-time high of 57\% on during that decade (Camp, 2012), but the share of computing degrees granted to women out of this approximated 17\%. The participation of women and minorities at the graduate levels is equally alarming. As a telling example, only 354 (22.4\% of total) and 60 (3.8\% of total) Ph.D. degrees in IT in the United States were awarded to women and minorities, respectively, in 2008-09 (Camp, 2012).

Does this lack of participation/diversity signal a serious national educational problem? Certainly the computing and information technology field is missing the additional talent and perspective that women bring into the work force (Balcita et al, 2002). Additionally, even the individual woman is missing out on career advancements and job opportunities, which are available in computing related fields. Considering that IT work is well-compensated and rewarding, this gender inequality in this particular field has long-term socio-economic implications.

To understand these issues clearly from an educator perspective, we have conducted a longitudinal study analyzing the student data for a period of 2001-2012, a period of 12 years. This study focuses on female enrollment with majors in computer information systems. As stated, since 2000 there has been a decline in enrollment in IT majors throughout the university for both men and women. Women majoring in IT have decreased significantly in the last ten-year period. The dramatic decline in female enrollment started in 2003 and reached its nadir in 2007 when there were no freshmen women majoring in information technology at this university. A positive sign that women may again seek degrees in information technology has been the freshmen class for the fall 2012 term. Freshmen enrollment has increased by $300 \%$ over the prior term for women majors. Throughout the university, undergraduate information technology enrollment is 339 students. Of these, 261 are male and 78 female, a $28 \%$ difference in gender preference for the major.

The research questions posed in this study are: 


\section{Issues in Information Systems}

Volume 14, Issue 1, pp.260-268, 2013

RQ1: Is there a difference between SAT scores (Math, Verbal and Total) of incoming freshmen students, male and female, who are enrolled in the CIS (Computer Information Systems) program?

RQ2: Did the genders perform differently based on their incoming SAT scores and their final GPAs? Is the correlation between the incoming SAT scores and outgoing GPA figures different between the gender of students in CIS majors?

RQ3: Is there a correlation between students aptitude for CIS courses (measured by SAT) and their ability to perform well in the CIS program as measured by their final GPA?

RQ4: Are there enrollment pattern differences by gender over the past 12 years?

The remainder of the paper is organized with the initial section as a review of relevant research literature in the area of women in information technology curriculum and careers. The literature review section is followed by the results section that discusses the data collection and data analysis steps performed for this study. The test results are presented and explained in the context of the study. After presenting the results of the analysis, the discussion section establishes the significance of the results of this study, both in terms of further research and useful findings for the practitioner. The contributions and limitations are presented and major conclusions drawn.

\section{LITERATURE REVIEW}

This section presents a critical review of the research in the area of women in information technology, computing curriculum and technology fields as career options. Before we delve into the research studies in this area, we need to establish the definition of computing, computing courses and what it means to have a job or career in the computing filed. Computing courses are those that involve specific training on the artifacts, operations and usages of computing. They include but are not limited to courses in software, hardware, systems development, security of information, database development or information management. A computing career generally requires a 4-year degree in the computing field with extensive work experience in computing courses as described. Some of the job titles that are included would be computer programmer, computer software engineer, computer hardware engineer, database analyst, network specialist, security specialist, IT audit, data communication and project management to name a few. The authors also acknowledge that even though there are definitional differences in the terms "information systems", "information technology", "computing", "software engineering" and "computer science", for the sake of this study these terms are used to convey the same broader concept of "technology" usage.

There have been several studies that explore the traits and image of information technology discipline as a major and also as a career. IT as a profession has been generally associated with masculine traits such as intellect, logic, scientific and technical skills, whereas femininity is often associated with intuition, emotion, social/soft technical skills and teamwork organization. This widely held perception of fields greatly impacts the allocation of skill labels, status, prestige, skill rewards and organization of work in professions (Trauth and Quesenberry, 2006). Several studies have concluded that even though IT jobs are described as interesting and challenging, IT professionals are often perceived as "geeks" or "nerds" who can relate to machines more than people (Zhang, 2007). The geeky image of IT professionals could negatively affect students' attitude towards choosing an IS major. Gavin (1998) researched student's interest in mathematics and science among students with high ability for mathematics. He reported that the usefulness of mathematics courses was rated higher by the males than by the females. Having a positive attitude towards the usefulness of mathematics is an important factor in a women's choice in mathematics-oriented careers (Gavin, 1998). This widely held belief that women are not strong in mathematics and technology and hence hesitate to pick information systems as a major led us to the research questions in this study.

There have been several studies that examined why women leave computing when they enter college. The Association for Computing Machines (ACM) conducted a study in this area and reported that factors that influence young women dropping out of computer science degrees include: social perception of computing jobs (heavily male dominated), lack of mentoring and role models, and gender discrimination (Pearl et al, 1990). Correll (2001) argues that female students having the same grades and test scores in math as male students still perceived themselves as less competent in mathematics as their counterparts. So the self-efficacy resulting from actual competency in a domain may not be enough for a female to choose a particular major. Turner and Brown (1999) also include labor market expectations and expected college experiences as important parameters in choosing a major. Deeply rooted expectations about the social roles of women may have led female students to view an IS career as a less preferred major (Zhang, 2007). The opinion of students' families and professor were consistent with the dominant socialization pattern that information technology is not meant for female students. Zhang (2007) explored how gender affects students intentions to choose an IS major, the gender differences in behavioral beliefs, normative beliefs, attitudes towards the IS major, subjective norms and intentions to choose IT majors. This study also suggests that females students were socially discouraged from pursuing an IS major. Female students seemed to believe that they were less often expected to choose an IS major than male students, and unlike male students, they weighed others' 


\section{Issues in Information Systems \\ Volume 14, Issue 1, pp.260-268, 2013}

opinions when forming their intentions (Zhang, 2007). Based on the review of the literature, this study is motivated to understand if there is a significant difference between abilities of men and women in mathematical capability as reflected by their SAT (Mathematics) scores or their cumulative GPA as they graduate with an undergraduate degree. The following section presents the methodology section of this research.

\section{DATA COLLECTION AND ANALYSIS}

This study analyzes the student data from a mid-size private university in North Eastern United States. This particular university has an undergraduate enrollment of 4,700 students and 1,100 masters and doctoral students. The gender breakdown for the undergraduate student body is 2,558 (54.42\%) male and 2,142 945.57\%) females. The data was gathered from a historical data warehouse containing incoming student data and final GPA records for the entire university. After the CIS data was retrieved it was de-identified before being analyzed in SPSS version 19. The data shows the rapid decline in enrollment and slow recovery in CIS at the school for both genders (see Figure 1 and 2).

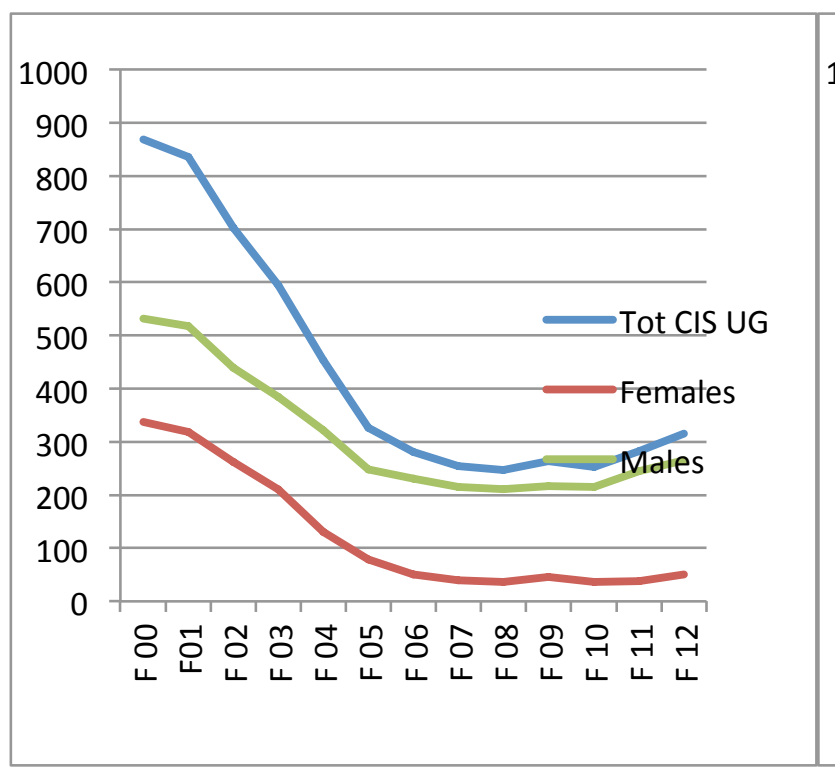

Figure 1: Total CIS enrollment

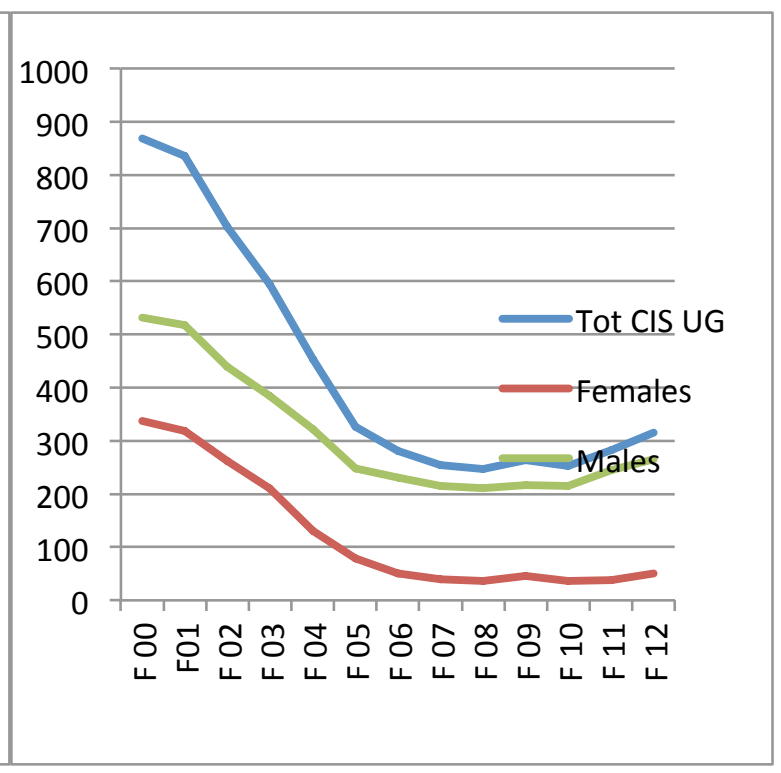

Figure 2: CIS Freshmen Enrollment

Data gathered over 12 years (2001 through 2012) included 59 females and 367 males, all majors in the CIS department. For incoming freshman of both genders, the SAT math mean was 505, verbal 513, total of 1004 , a final GPA of 2.79 and a median GPA of 2.98 .

Table 1: Total Enrollment over 2001-2012

\begin{tabular}{|c|c|c|c|c|}
\hline & & \multicolumn{2}{|l|}{ Gender } & \multirow[b]{2}{*}{ Total } \\
\hline & & $\mathrm{F}$ & M & \\
\hline \multirow[t]{8}{*}{ term } & 2001 & 9 & 53 & 62 \\
\hline & 2002 & 12 & 56 & 68 \\
\hline & 2003 & 4 & 34 & 38 \\
\hline & 2004 & 4 & 31 & 35 \\
\hline & 2005 & 5 & 14 & 19 \\
\hline & 2006 & 3 & 21 & 24 \\
\hline & 2007 & 0 & 12 & 12 \\
\hline & 2008 & 2 & 24 & 26 \\
\hline
\end{tabular}


Volume 14, Issue 1, pp.260-268, 2013

\begin{tabular}{|c|c|c|c|}
\hline 2009 & 3 & 25 & 28 \\
\hline 2010 & 4 & 29 & 33 \\
\hline 2011 & 3 & 33 & 36 \\
\hline 2012 & 10 & 35 & 45 \\
\hline Total & 59 & 367 & 426 \\
\hline
\end{tabular}

RMU female enrollment dropped considerably as is clear from the data presented above. This led us to our first research question: Are the female students that we recruit into CIS different than the male students (in terms of SAT scores) and did they perform differently in terms of their cumulative GPA?

An ANOVA was conducted comparing the means for SATM, SATV SATTT and final GPA between the genders.

Table 2: ANOVA scores

\begin{tabular}{|c|c|c|c|c|c|c|}
\hline & & Sum of Squares & $\mathrm{df}$ & Mean Square & $\mathrm{F}$ & Sig. \\
\hline \multirow[t]{3}{*}{ SATM } & Between Groups & 20073.496 & 1 & 20073.496 & 3.500 & .062 \\
\hline & Within Groups & 2156550.049 & 376 & 5735.505 & & \\
\hline & Total & 2176623.545 & 377 & & & \\
\hline \multirow[t]{3}{*}{ SATV } & Between Groups & 99637.090 & 1 & 99637.090 & 16.054 & .000 \\
\hline & Within Groups & 2333653.122 & 376 & 6206.524 & & \\
\hline & Total & 2433290.212 & 377 & & & \\
\hline \multirow[t]{3}{*}{ SATOT } & Between Groups & 1395923.163 & 1 & 1395923.163 & 57.345 & .000 \\
\hline & Within Groups & 9177166.547 & 377 & 24342.617 & & \\
\hline & Total & 10573089.710 & 378 & & & \\
\hline \multirow[t]{3}{*}{ RMU_GPA } & Between Groups & .465 & 1 & .465 & .607 & .436 \\
\hline & Within Groups & 316.439 & 413 & .766 & & \\
\hline & Total & 316.904 & 414 & & & \\
\hline
\end{tabular}

No statistical differences were found. This would reveal that there wasn't a difference in the incoming students SAT scores, or their final GPA.

This leads us to our second research question: Did the genders perform differently based on their incoming SAT scores and their final GPAs? Is there a correlation between the incoming SAT scores and outgoing GPA?

Table 3: Correlation between SAT measures (all three) and Final GPA

\begin{tabular}{|c|c|c|c|c|c|}
\hline & & SATM & SATV & SATOT & RMU_GPA \\
\hline \multirow[t]{3}{*}{ SATM } & Pearson Correlation & 1 & $.556^{* *}$ & $.744^{* *}$ & $.306^{* *}$ \\
\hline & Sig. (2-tailed) & & .000 & .000 & .000 \\
\hline & $\mathrm{N}$ & 378 & 378 & 378 & 368 \\
\hline \multirow[t]{3}{*}{ SATV } & Pearson Correlation & $.556^{* *}$ & 1 & $.790^{* *}$ & $.332^{* *}$ \\
\hline & Sig. (2-tailed) & .000 & & .000 & .000 \\
\hline & $\mathrm{N}$ & 378 & 378 & 378 & 368 \\
\hline \multirow[t]{2}{*}{ SATOT } & Pearson Correlation & $.744^{* *}$ & $.790^{* *}$ & 1 & $.330^{* *}$ \\
\hline & Sig. (2-tailed) & .000 & .000 & & .000 \\
\hline
\end{tabular}


Issues in Information Systems

Volume 14, Issue 1, pp.260-268, 2013

\begin{tabular}{|rl|r|r|r|r|}
\hline \hline & $\mathrm{N}$ & 378 & 378 & 379 & 369 \\
\hline RMU_GPA & Pearson Correlation & $.306^{* *}$ & $.332^{* *}$ & $.330^{* *}$ & .000 \\
& Sig. (2-tailed) & .000 & .000 & .000 \\
$\mathrm{~N}$ & 368 & 368 & 369 & 415 \\
\hline
\end{tabular}

**. Correlation is significant at the 0.01 level (2-tailed).

Correlations between all three SAT measures and the final GPA were significant and less than .01 for the combined genders. For men only, the correlations were again significant and less than .01 for all three measures, but the SATV and SAT Totals were higher at .332 vs. .343 for verbal and .369 vs. .330 for total.

Table 4: Correlation between SAT components and final GPA (Men)

\begin{tabular}{|c|c|c|c|c|c|}
\hline & & SATM & SATV & SATOT & RMU_GPA \\
\hline \multirow[t]{3}{*}{ SATM } & Pearson Correlation & 1 & $.549^{* *}$ & $.874^{* *}$ & $.306^{* *}$ \\
\hline & Sig. (2-tailed) & & .000 & .000 & .000 \\
\hline & $\mathrm{N}$ & 328 & 328 & 328 & 327 \\
\hline \multirow[t]{3}{*}{ SATV } & Pearson Correlation & $.549^{* *}$ & 1 & $.886^{* *}$ & $.343^{* *}$ \\
\hline & Sig. (2-tailed) & .000 & & .000 & .000 \\
\hline & $\mathrm{N}$ & 328 & 328 & 328 & 327 \\
\hline \multirow[t]{3}{*}{ SATOT } & Pearson Correlation & $.874^{* *}$ & $.886^{* *}$ & 1 & $.369^{* *}$ \\
\hline & Sig. (2-tailed) & .000 & .000 & & .000 \\
\hline & $\mathrm{N}$ & 328 & 328 & 328 & 327 \\
\hline \multirow[t]{3}{*}{ RMU_GPA } & Pearson Correlation & $.306^{* *}$ & $.343^{* *}$ & $.369^{* *}$ & 1 \\
\hline & Sig. (2-tailed) & .000 & .000 & .000 & \\
\hline & $\mathrm{N}$ & 327 & 327 & 327 & 366 \\
\hline
\end{tabular}

**. Correlation is significant at the 0.01 level (2-tailed).

Table 5: Correlation between SAT components and final GPA (Women)

\begin{tabular}{|c|c|c|c|c|c|}
\hline & & SATM & SATV & SATOT & RMU_GPA \\
\hline \multirow[t]{3}{*}{ SATM } & Pearson Correlation & 1 & $.565^{* *}$ & $.307^{*}$ & $.392^{*}$ \\
\hline & Sig. (2-tailed) & & .000 & .030 & .011 \\
\hline & $\mathrm{N}$ & 50 & 50 & 50 & 41 \\
\hline \multirow[t]{3}{*}{ SATV } & Pearson Correlation & $.565^{* *}$ & 1 & $.376^{* *}$ & $.390^{*}$ \\
\hline & Sig. (2-tailed) & .000 & & .007 & .012 \\
\hline & $\mathrm{N}$ & 50 & 50 & 50 & 41 \\
\hline \multirow[t]{3}{*}{ SATOT } & Pearson Correlation & $.307^{*}$ & $.376^{* *}$ & 1 & .230 \\
\hline & Sig. (2-tailed) & .030 & .007 & & .144 \\
\hline & $\mathrm{N}$ & 50 & 50 & 51 & 42 \\
\hline
\end{tabular}


Volume 14, Issue 1, pp.260-268, 2013

\begin{tabular}{|ll|r|r|r|r|}
\hline \hline RMU_GPA & Pearson Correlation & $.392^{*}$ & $.390^{*}$ & .230 & \\
& Sig. (2-tailed) & .011 & .012 & .144 & \\
& $\mathrm{~N}$ & 41 & 41 & 42 & \\
& \\
\hline
\end{tabular}

**. Correlation is significant at the 0.01 level (2-tailed).

*. Correlation is significant at the 0.05 level (2-tailed).

The correlations of SAT to final GPA in women was lower even though overall, the ANOVA showed no differences in the means SAT values or the mean GPA's. This demonstrates that, on an overall basis, the student's performance in the program for men and women did not match the expected performance level based on their GPA values, but that the variance between the SAT and final GPA was not in one direction.

Table 6: ANOVA grouped by Gender

\begin{tabular}{|c|c|c|c|c|c|c|}
\hline & & Sum of Squares & df & Mean Square & $\mathrm{F}$ & Sig. \\
\hline \multirow[t]{3}{*}{ SATM } & Between Groups & 20073.496 & 1 & 20073.496 & 3.500 & .062 \\
\hline & Within Groups & 2156550.049 & 376 & 5735.505 & & \\
\hline & Total & 2176623.545 & 377 & & & \\
\hline \multirow[t]{3}{*}{ SATV } & Between Groups & 99637.090 & 1 & 99637.090 & 16.054 & .000 \\
\hline & Within Groups & 2333653.122 & 376 & 6206.524 & & \\
\hline & Total & 2433290.212 & 377 & & & \\
\hline \multirow[t]{3}{*}{ SATOT } & Between Groups & 1395923.163 & 1 & 1395923.163 & 57.345 & .000 \\
\hline & Within Groups & 9177166.547 & 377 & 24342.617 & & \\
\hline & Total & 10573089.710 & 378 & & & \\
\hline \multirow[t]{3}{*}{ RMU_GPA } & Between Groups & .465 & 1 & .465 & .607 & .436 \\
\hline & Within Groups & 316.439 & 413 & .766 & & \\
\hline & Total & 316.904 & 414 & & & \\
\hline
\end{tabular}

Since we noted such differences in recruiting women into the CIS programs, an ANOVA was run on SAT and GPA values for both genders across all of the recruiting years. We wanted to check if there were differences within genders on the type of students recruited or their performance as measured by GPA.

We then tested ANOVA for men and women separately for the given period of 2001-2012. There were no differences in SAT verbal, SAT math SAT Total or final GPA for women across the 12 years. This was essentially the same as for the men. Thus, even though the actual numbers were down for women across all of those years, their incoming SAT scores and final GOA were quite consistent. The students remained similar in ability, as measured by SAT and their performance in the program, as measured by GPA.

\section{DISCUSSIONS}

Our results suggest that there are no differences between men and women enrolling in CIS programs based on their SAT scores. This suggests that the assumption that women inherently lack the abilities or skills to consider CIS as a major is not proven, but rather that there are differences in their approach towards CIS based on other factors. Also, when we examined the difference in genders based on their graduating mean GPA to see if there was some indication of male and female discrepancies based on their incoming SAT and outgoing GPAs, we did not find any significant relationship (see table 7 for summary of results). Correlations between SAT and GPA were different for men, even though their overall final 


\section{Issues in Information Systems \\ Volume 14, Issue 1, pp.260-268, 2013}

GPA means were the same. The predictability of incoming SAT was not the same for men and women. Finally, for our last research question, even though enrollment was down for men and women, enrollment criteria as measured by incoming SAT scores did not deviate for the different genders. The significance of the results obtained in this study indicates that, on an overall basis, the research literature in this area agrees with the direction of the findings of this particular study.

Table 7: Summary of findings

\begin{tabular}{|lll|}
\hline Question & Result & Discussion \\
\hline $\begin{array}{l}\text { RQ1: Is there a difference between in SAT scores (Math, } \\
\text { Verbal and Total) of incoming freshmen students, males } \\
\text { and females, who are enrolled in CIS program? }\end{array}$ & & $\begin{array}{l}\text { No differences in men and women } \\
\text { SAT scores }\end{array}$ \\
\hline $\begin{array}{l}\text { RQ2: Did the genders perform differently based on their } \\
\text { incoming SAT scores and their final GPAs? Is the } \\
\text { correlation between the incoming SAT scores and } \\
\text { outgoing GPA different between genders of students in } \\
\text { CIS majors? }\end{array}$ & No differences & $\begin{array}{l}\text { No differences in MEAN GPA for } \\
\text { men and women }\end{array}$ \\
\hline $\begin{array}{l}\text { RQ3: Is there a correlation between students aptitude for } \\
\text { CIS courses (measured by SAT) and their ability to } \\
\text { perform well in CIS program s (as measured by their } \\
\text { final GPA)? }\end{array}$ & Difference & $\begin{array}{l}\text { Correlations between SAT and GPA } \\
\text { were different for men, even though } \\
\text { their overall final GPA means were } \\
\text { the same. The predictability of } \\
\text { incoming SAT differed for men and } \\
\text { women. }\end{array}$ \\
\hline $\begin{array}{l}\text { RQ4: Are there enrollment pattern differences by gender } \\
\text { over the past 12 years? }\end{array}$ & $\begin{array}{l}\text { Across all the } \\
\text { years, there was } \\
\text { no significant } \\
\text { difference in } \\
\text { incoming SAT } \\
\text { scores for men } \\
\text { and women }\end{array}$ & $\begin{array}{l}\text { Even though enrollment was down } \\
\text { for men and women, enrollment } \\
\text { criteria as measured by incoming } \\
\text { SAT scores did not deviate for the } \\
\text { different genders. }\end{array}$ \\
\hline & \\
\hline
\end{tabular}

The research literature suggests that male college graduates have more confidence in their computing abilities than their female counterparts, especially when they begin college, even though females might end up getting higher grades than the males (Prey and Treu, 2002). Overall, women are avoiding considering at computing studies as a major due to broader reasons beyond the difficulty level of the content.

Trauth et al (2009) examines three important organizational factors that affect women's retention in the IT field: work-life balance, organizational climate, and mentoring. This study uses a basic assumption that not all women are similar and hence different characteristics can affect them in different outcomes. The researchers suggest that a woman's demographic and professional characteristics affect her career choices. They also propose that the ways in which differences in personality, abilities, and influential people interactions can shape one's career. The environmental influences construct characterized contextual influences on women's participation in the IT profession (Trauth, et al, 2009). Gender differences in the choice of college majors have been found to be a key contributor to the persistent low number of women CIS enrollments (BecerraFernandez et al, 2010). Some reports attribute this difference to the fact that IT workplaces (and university classrooms) lack interpersonal orientation, resulting in an inhospitable male dominated environment (Becerra-Fernandez et al, 2010). Other reports point out that the influence and attitude towards CIS may be best instilled by a girl's parents and early positive experiences with technology shaping their early interests (Becerra-Fernandez et al, 2010).

The studies suggest certain problems that women encounter in considering a career in information technology: Information systems courses have a reputation for being boring and not giving the students creative freedom, which discourages women from entering the field (Vilner and Zur, 2006). Additionally, women tend to have less significant hands-on experiences than men in most aspects of computing which can hinder their chances of obtaining a degree in information systems. CIS or IT students usually suffer from the derogatory "nerd" image, that is a portrayal of people who are obsessed with the computer 


\section{Issues in Information Systems}

Volume 14, Issue 1, pp.260-268, 2013

technical experience and spend a great deal of time engaged in it, thus tending to consider social skills as less useable than computer skills. This stereotype is more damaging for women than for men (Vilner and Zur, 2006). We infer that there are deeper sociological and psychological reasons regarding this trend of women not fully participating in computing education and careers in a systematic way. To address some of the issues listed above in this section, there are several strategies that could be adopted. Developing courses that are more engaging for women by reflecting the relevance of computers to actual life strategies, for instance, would be a strong incentive to increase female participation (Viliner and Zur, 2006). Designing curricular offerings that provide more creative freedom and counter the image of narrow computer specialization as the only viable path to career advancement might generate a more desirable response by the female component.

Recognizing the importance of female role models in IT by employing more women as lecturers and teaching assistants allows a role model approach to connect students with the profession and its demands at a personal level (Viliner and Zur, 2006). IT professors have much to do to improve the current gender bias in the IT major. The perceived difficulty of the IT curriculum negatively affects attitudes toward choosing the designated major (Zhang, 2007). Also, professors are identified as a salient reference group that influences student choices. Thus, ITS professors can offset the preconception of students about IT being a difficult major to pursue and explicitly promote IT as a viable major option considering the market realities. Building a student organization and designing activities and events that can encourage and support a community of women in their career choices has a significant collegiate success correlation. Vilner and Zur (2006) argue that in the theoretical courses based on theoretical thinking and analyzing rather than on technical capabilities like programming, women can succeed as well as men. In these courses the gap in the hands-on experience in computing between men and women as described in the literature is not reflected.

\section{Contributions}

This study contributes on several accounts both to research literature and to practitioners who want to see more women in computing degrees and in the computing workforce. Theoretically, this research suggests that looking at SAT scores of men and women while they are considering the majors in CIS is not a significant factor. SAT scores, in this analysis, are not a good predictor of the choice of major based on the gender of the student. Secondly, this research suggests that both male and female students need to exhibit a strong work ethic in their composite studies in the computing field, and that neither gender has an upper hand in their abilities as indicated by their cumulative GPA. Finally, SAT does not suggest any pattern in enrollment of men and women in computing degrees. For practitioners, there are several contributions from this research. First, this research suggests that men and women are not very different in their aptitude for being trained in a computing field. The fact that women are not responsive to the IT educational experience has little to do with their ability to perform well in a computing career as suggested by our results. The research effort can confidently conclude that women are capable of achieving comparable GPA scores to that obtained by men in any technology related curriculum. Finally, the deeper sociological and psychological reasons for women not exploring their potential in the field of computing requires long-term planning and focused strategies to develop solutions to the problem. An understanding of these issues along with the suggested techniques would be beneficial in their efforts to involve more women in the field of computing.

\section{Limitations and Future Research}

This study has its own set of limitations. First, all the data that we have analyzed here is from one particular university. It could be possible that the trends and the results of this study are reflective of characteristics unique to this particular institution. It would be beneficial to generate similar data from universities of varying sizes and resources in other areas of the nation. Second, considering SAT and GPA as a predictor of academic success of a students is an over simplification of the actual phenomenon. There are several other factors that would impact the GPA of students in computing degrees other than their gender. It would be quite informative to create a multi-level model consisting of social, cultural, economic and attitudinal factors that impact the choice of majors for women, essentially in the context of various computing disciplines. This could be a plausible area of future research. The use of complex measures in this study to understand this phenomenon is limited at best.

\section{CONCLUSIONS}

The purpose of this study was to understand the relationships between SAT scores, final GPA, enrollment trends of males and females entering into undergraduate computing programs. This study has used the data from a medium sized university in the northeastern section of the United States over a period of 12 years, with the intent to analyze the pattern in enrollment of males and females in computing programs. The results suggest that there is no apparent relationship between incoming SAT scores of students (both males and females) and their outgoing GPAs in tandem with their preference for the computing major. An ANOVA test was performed on the enrollment data collected from the university to arrive at the above results. 


\section{Issues in Information Systems}

Volume 14, Issue 1, pp.260-268, 2013

There are contributions of this work to theory and to practitioners. The limitations of this study are noted with the suggestion that the most relevant limitation is that the entire study is based on the data from one particular university. Future research areas are suggested.

\section{REFERENCES}

1. Balcita, A. M., Carver, D. L. and Soffa, M.L. (2002). Shortchanging the future of information technology: the untapped resource. ACMSIGCSE Bulletin, 34(2), 32-35

2. Becerra-Fernandez, I., Elam, J. and Clemmons, S. (2010). Reversing the Landslide in Computer-Related Degree Programs, Communications of the ACM, 53(2), February 2010

3. Bureau of Labor Statistics, U.S. Department of Labor, The Editor's Desk, Fastest growing jobs, 2000-2010 on the Internet at http://www.bls.gov/opub/ted/2001/dec/wk1/art02.htm (visited February 18, 2013)

4. Camp, T. (2012). Computing, We Have a Problem..., ACM Inroads, 3(4), 2012 December

Carter, L. (2006). Why Students with an Apparent Aptitude for Computer Science Don't Choose to Major in Computer Science. Proceedings of the 37th SIGCSE Technical Symposium on Computer Science Education, Houston, TX, March 2006.

5. Computing Research Association. 2004. The Supply of Information Technology Workers in the United States, Chapter 2 Information Technology Workers. Retrieved on 12/21/2004 http://www.cra.org/reports/wits/chapter_2.html

6. Darrah, M., Giorcelli, R. and Dodson, T. (2007) Comprehensive Program for Expanding Pathways to IT Careers, SIGITE'07, October 18-20, 2007, Destin, Florida, USA

7. Gavin, M.J. (1998). A gender study of students with high mathematics ability: personological, educational, and parental variables related to the intent to pursue quantitative fields of study. Dissertation Abstracts International, 58(08), 3052A.

8. Kolacz-Belanger,V. (2008). Women of opportunity: Characteristics of experienced women in computing and information technology careers, ProQuest Dissertations and Theses; 2008; Proquest

9. Outlay, C., Ambrose, P. and Chenoweth, J. (Overcoming Gender Stereotype Entry Barriers to Computing Degree Programs: The Cybergirlz Program Experience, JCSC, 28(1), October 2012

10. Prey, J. and Treu, K. (2002). What do you say? Open letters to women considering a computer science major. ACM SIGSCE Bulletin, 34(2), 18-20.

11. Pearl, A., Polloack, M.E., Riskin, E., Thomas, B., Wolf, E. and Wu, A. (1990). Becoming a computer scientist. Communications of the ACM, 33(11), 47-57

12. Trauth, E. and Quesenberry, J. (2006). Are Women an Underserved Community in the Information Technology Profession? Twenty-Seventh International Conference on Information Systems, Milwaukee 2006

13. Trauth, E., Quesenberry, J and Huang, H. (2009). Retaining women in the U.S. IT workforce: theorizing the influence of organizational factors, European Journal of Information Systems (2009) 18, 476-497

14. Vilner, T. and Zur, E. (2006). Once She Makes it, She is There: Gender Differences in Computer Science Study, ITiCSE 2006, June 26-28, 2006, Bologna, Italy

15. Women in Technology (2013). Retrieved on 02/19013 http://www.womenintechnology.org/witef/about-us

16. Wright, B. (2009). Employment, trends, and training, Occupational Outlook Quarterly, Spring 2009, Retrieved from http://www.bls.gov/opub/ooq/2009/spring/art04.pdf

17. Zhang, W. (2007). Why IS: Understanding Undergraduate Students' Intentions to Choose an Information Systems Major, Journal of Information Systems Education; Winter 2007; 18, 4; ProQuest Central, pg. 447 